\section{Error, Sources of}

Michael Franzen

Allegheny General Hospital, Pittsburgh, PA, USA allow an estimate and correction of the error term so as to maximize the extent to which an observed score reflects the true value of the construct of interest.

\title{
Definition
}

\section{Cross-References}

Sources of error are the factors that influence a test score or item performance that are extraneous to the construct of interest. Because these are not related to the construct, they are errors in the measurement process. In a memory test, sources of error might include examiner imprecision or subjectivity, fatigue, time of day, or level of hunger. The effects of these sources comprise the error term in classical test theory. Test construction is conducted so as to minimize or otherwise

- Classical Test Theory

- Test Reliability

- Test Validity

\section{References and Readings}

Kline, P. (1986). A handbook of test construction: Introduction to psychometric design. New York: Methuen. 